\section{Screening and counselling of school-leavers for the carrier state of hereditary anaemias}

Antenatal diagnosis of genetic diseases has sharpened interest in the discovery of symptomless carriers under childbearing age. This is true of the haemoglobinopathies and may well spread to other conditions. In the pasi attempts at population screening have met with a mixed reception and involved both technical and counselling problems. ${ }^{1-4}$

A pilot study was carried out as part of the normal health education given to schoolchildren in the fifth form, mostly 16-year-olds. These young adults were old enough to understand the counselling and also close to the onset of childbearing age. The counselling could be done individually in a familiar school atmosphere and reinforced during classes on health education.

\section{Subjects, methods, and results}

An inner city comprehensive school in Luton was chosen because of its high proportion of children of immigrant families. A class of 124 was given a talk after an introduction by the head teacher. Forms were given to each child asking for the ethnic origin of each parent, whether they were cousins, whether there was a family history of severe anaemia, and requesting parental consent to examine a blood sample. The children were selected for screening on the basis that one or both parents belonged to an ethnic group at risk of haemoglobinopathy and glucose-6-phosphate dehydrogenase deficiency.

\section{SCREENING FOR HAEMOGLOBINOPATHIES}

A 4-ml sample of venous blood was obtained for Coulter Model S profile, screening for glucose-6-phosphate dehydrogenase deficiency, haemoglobin electrophoresis, and blood group analysis. A sickle test and fetal haemoglobin estimation were performed on selected specimens. Three additionalspecimens were assayed for ferritin. Specimens from two Asian girls who complained of pain in their legs were tested for biochemical confirmation of rickets.

The results of screening are given in the table. From the total of 124, 80 subjects were selected for counselling and 50 attended. Of these, 18 boys and 11 girls were Asians, three-quarters of the Asian group attending for counselling. Nine boys and six girls were West Indians, only one-third of this ethnic group attending. Two subjects were Chinese, three Italian (two boys and one girl), and one was of mixed Italian and Greek origin.

COUNSELLING

The haematological abnormalities which were found in a quarter of the group could be divided into acquired abnormalities, treatment of which could be beneficial, and inherited abnormalities, which were harmless to the individual but of genetic significance (see table).

Haemoglobinopathies found by screening of 124 schoolchildren of different ethnic origins

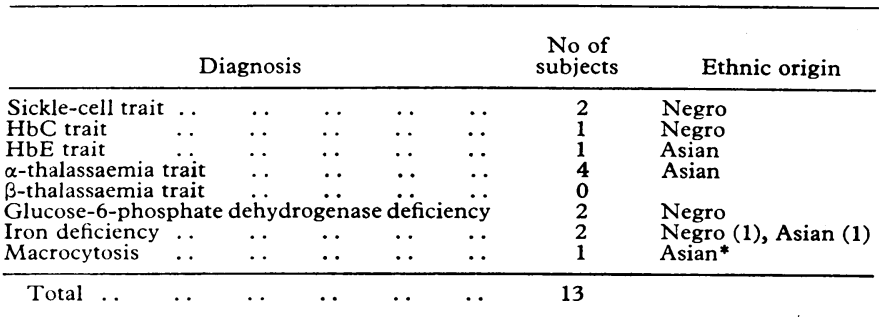

*This girl and her sister also had adolescent rickets.

Counselling was given in the school medical room by one of us (EHL). Each person was seen individually (except on one occasion when two girls asked to be seen together) and was told that he or she was a carrier of a trait, emphasising that this would cause no symptoms. The possibility of the disease state existing in 1 in 4 children was illustrated by a simple diagram of two parents who were carriers. The techniques of antenatal diagnosis were explained and a short written account of the verbal counselling was given to each child to take home for future reference and for the information of the parents. In addition, the children took home the laboratory result, which they were instructed to give to their family doctor. Glucose-6 phosphate dehydrogenase deficiency was explained and a list of drugs to be avoided handed to the relevant subjects. Those with iron deficiency anaemia were given dietary advice and told to go to their family doctor for treatment.

All except one girl accepted the counselling well. They seemed to understand the genetic implications and the help that was available. The remainder of the class were not told who the affected people were. The girl (of West Indian origin) who was upset by the information became surly and withdrawn; she was already known to be a dull difficult girl with an unhappy home background.

\section{Comment}

We think this screening and counselling service could be integrated into the general health education programme in schools where there are large numbers of children of non-English origin, since the cost is small. The factors necessary to make the service work are enthusiasm from the school doctor and health education teacher and a helpful haematology laboratory at the district general hospital. We also recommend that all Asian girls could be screened biochemically for subclinical adolescent rickets.

We wish to thank Mrs V Mitchell-Rawles, OBE, head teacher, Beech Hill High School, Luton, for her help.

Further details of laboratory technique can be obtained from Dr D S Thompson and those of counselling and organisation from $\mathrm{Dr} \mathrm{E}$ de $\mathrm{H}$ Lobo.

${ }^{1}$ Whitten CF. Sickle cell programming, an imperiled promise. $N$ Engl $\mathfrak{f}$ Med 1973;288:318-9.

2 Silvestroni E, Bianco I. Screening for thalassaemia. Lancet 1975;i:1100.

${ }^{3}$ Modell B, Ward RHT, Fairweather DVI. Effect of introducing antenatal diagnosis on reproductive behaviour of families at risk for thalassaemia major. $\mathrm{Br} \mathrm{Med} \mathcal{F} 1980 ; 280: 1347-50$.

${ }^{4}$ Stuart J, Schwartz FCM, Little AJ, Raene DN. Screening for abnormal haemoglobulins: a pilot study. Br Med f 1973;ii:284-7.

(Accepted 8 February 1982)

Luton and Dunstable Hospital, Luton

E DE H LOBO, $F R C P(E), D C H$, consultant paediatrician

D S THOMPSON, MB, MRCPATH, consultant haematologist

\section{Aplastic anaemia associated with fenoprofen}

Fenoprofen is a widely prescribed non-steroidal anti-inflammatory propionic acid derivative used for osteoarthritis, rheumatoid arthritis, and ankylosing spondylitis. Reported haematological side effects include agranulocytosis, ${ }^{12}$ thrombocytopenia, ${ }^{34}$ and pure red-cell aplasia. ${ }^{5}$ We report two cases, one fatal, of aplastic anaemia associated with fenoprofen.

\section{Case reports}

Case 1-A 71-year-old woman was admitted to hospital with a two-week history of malaise, palpitations, dyspnoea, spontaneous bruising, and epistaxis and, for $\mathbf{4 8}$ hours, also haematuria and melaena. Ten months before admission she had noticed pain and stiffness in the fingers, wrists, shoulders, and knees and begun with fenoprofen $600 \mathrm{mg}$ thrice daily; this was continued until admission. Other medications received in the time included paracetamol, dihydrocodeine, aspirin, and intra-articular hydrocortisone. On admission she was anaemic and feverish. There were petechiae over the forearms and legs and bleeding ulcers on the buccal mucosa. The liver was palpable $2 \mathrm{~cm}$ below the costal margin and the rectum contained melaena. There was no lymphadenopathy and the spleen was not palpable. Investigations showed haemoglobin concentration $5.7 \mathrm{~g} / \mathrm{dl}$, leucocyte count $0.6 \times 10^{9} / 1\left(600 / \mathrm{mm}^{3}\right.$; neutrophils $15 \%)$, and platelet count $10 \times 10^{9} / 1\left(10000 \mathrm{~mm}^{3}\right)$. Sternal bone marrow aspirate and iliac trephine biopsy showed hypocellular marrow with no red-cell or neutrophil precursors and no megakaryocytes. Tests for antinuclear factor, rheumatoid factor, and LE cells gave negative results. Plasma urea and electrolyte concentrations were normal. Despite vigorous treatment 